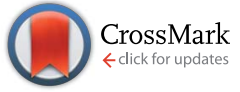

Cite this: Chem. Sci., 2016, 7, 3313

Received 28th December 2015

Accepted 9th February 2016

DOI: $10.1039 / \mathrm{c} 5 \mathrm{sc} 04984 a$

www.rsc.org/chemicalscience

\section{Asymmetric synthesis of allylic amines via hydroamination of allenes with benzophenone imine $\uparrow$}

\author{
Kun Xu, Yu-Hsuan Wang, Vahid Khakyzadeh and Bernhard Breit* \\ Rhodium-catalyzed highly regio- and enantioselective hydroamination of allenes is reported. Exclusive \\ branched selectivities and excellent enantioselectivities were achieved applying a rhodium(1)/Josiphos \\ catalyst. This method permits the practical synthesis of valuable $\alpha$-chiral allylic amines using \\ benzophenone imine as ammonia carrier.
}

$\alpha$-Chiral amines are of wide interest in organic synthesis ${ }^{1 a}$ due to their broad application in pharmaceutical research, ${ }^{1 b, c}$ catalysis $^{1 d, e}$ and natural product synthesis ${ }^{1 f}$ (Scheme 1). Among them, the synthesis of $\alpha$-chiral allylic amines is particularly important because of the versatility of the allylic moiety for further structural elaboration. ${ }^{2}$ In the past few decades, significant efforts have advanced the efficiency towards their synthesis. Many elegant approaches including allylic substitution, ${ }^{3}$ Overman rearrangements, ${ }^{4}$ allylic $\mathrm{C}-\mathrm{H}$ amination ${ }^{5}$ and imine vinylation ${ }^{6}$ have been reported. However, these methods need pre-installation of a leaving group or stoichiometric amounts of an oxidant/metal-containing reagent. In this regard, efficient synthetic methods for the synthesis of $\alpha$-chiral allylic amines are highly desirable.

The catalytic and enantioselective addition of simple ammonia $\left(\mathrm{NH}_{3}\right)$ to allenes would represent one of the most atom-economic transformation towards the synthesis of $\alpha$ chiral allylic amines. ${ }^{7-9}$ However, initial experiments revealed this transformation to be very challenging, presumably due to the following reasons: (1) the volatility and toxicity of gaseous

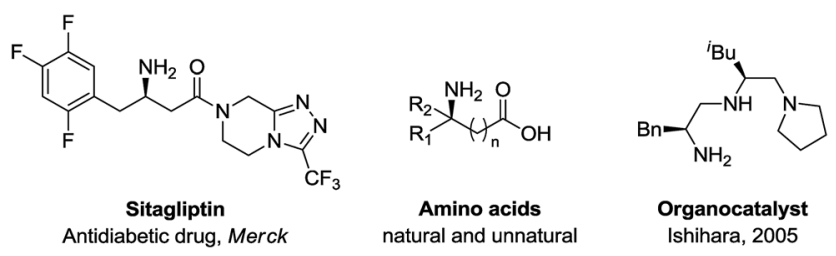

Scheme 1 Applications of $\alpha$-chiral amines.

Institut für Organische, Chemie Albert-Ludwigs-Universität Freiburg, Albertstrasse 21, 79104 Freiburg, Germany. E-mail: bernhard.breit@chemie.uni-freiburg.de; Fax: +49761-203-8715

$\dagger$ Electronic supplementary information (ESI) available: Experimental procedures and detailed characterization data of all new compounds. See DOI: $10.1039 / \mathrm{c} 5 \operatorname{sc} 04984 \mathrm{a}$
$\mathrm{NH}_{3}$ makes it less interesting in terms of practicality; (2) the catalytic systems were inactive in the presence of ammonia, possibly due to the high basicity of $\mathrm{sp}^{3}$ hybridized nitrogen atom, and its difficulty to undergo oxidative addition to a transition metal center. ${ }^{10}$

To address these issues, we assumed that the easy-to-use and $\mathrm{N}$-sp ${ }^{2}$-hybridized benzophenone imine ${ }^{11}$ could serve as an ammonia carrier: (1) benzophenone imine is commercially available and can be easily prepared via condensation of benzophenone with ammonia; ${ }^{12}$ (2) the $\mathrm{sp}^{2}$ hybridized imine nitrogen is more reactive towards allenes in the presence of a suitable transition metal catalyst; (3) the final $\alpha$-chiral primary allylic amines can be obtained via simple hydrolysis, and the benzophenone can be recycled (Scheme 2).

The initial assessment was performed by coupling cyclohexylallene and benzophenone imine using $\left[\{\mathrm{Rh}(\mathrm{COD}) \mathrm{Cl}\}_{2}\right](2.5$ mol\%) and racemic ligand 1,4-bis(diphenylphosphino)butane $(\mathbf{L} 1,10 \mathrm{~mol} \%)$ in 1,2-dichloroethane (DCE) at $80^{\circ} \mathrm{C}$ (Table 1 , entry 1). The reaction afforded the desired product with $10 \%$ NMR yield. We wondered whether addition of acid would facilitate the reaction by promoting the catalytic cycle. Indeed, both trifluoroacetic acid (TFA) and pyridinium $p$-toluenesulfonate (PPTS) could significantly improve the yield, while the addition of $p$-toluenesulfonic acid (PTSA) had no effect (Table 1, entry 2-4). These promising results encouraged us to

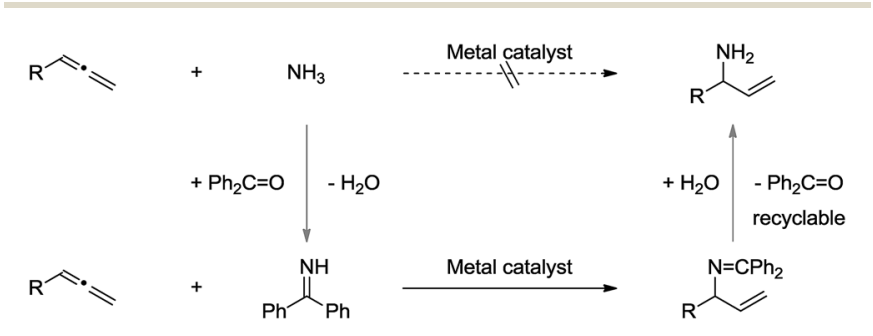

Scheme 2 Proposed synthesis of $\alpha$-chiral allylic amines using benzophenone imine as ammonia carrier. 
Table 1 Reaction development

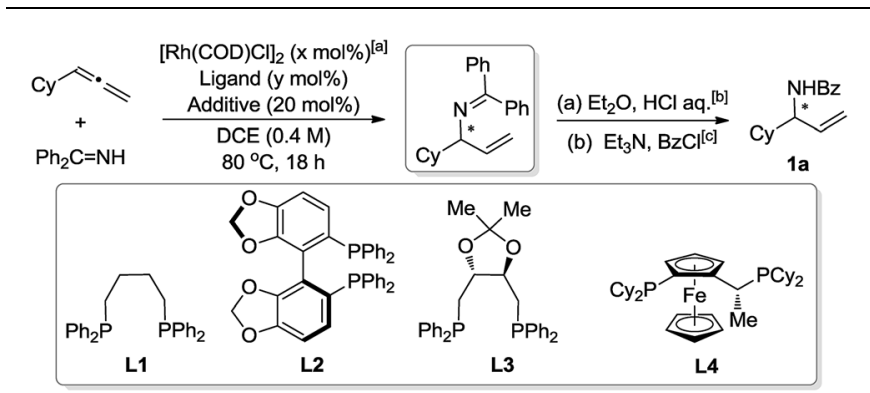

\begin{tabular}{llllll}
\hline Entry & $x$ & Ligand $(y)$ & Additive & Yield $^{d} \%$ & $\mathrm{ee}^{e} / \%$ \\
\hline 1 & 2.5 & L1 (10) & - & $(10)$ & - \\
2 & 2.5 & L1 (10) & PTSA & $(11)$ & - \\
3 & 2.5 & L1 (10) & TFA & $(50)$ & - \\
4 & 2.5 & L1 (10) & PPTS & $(65)$ & - \\
5 & 2.0 & L1 (4.0) & PPTS & $(59)$ & - \\
6 & 2.0 & L2 (4.0) & PPTS & $(10)$ & - \\
7 & 2.0 & L3 (4.0) & PPTS & $76^{f}$ & $54^{g}$ \\
8 & 2.0 & L4 (4.0) & PPTS & $72^{f}$ & 92
\end{tabular}

${ }^{a}$ Benzophenone imine (1.0 equiv.), cyclohexylallene (1.5 equiv.). ${ }^{b} \mathrm{Et}_{2} \mathrm{O}$ $(2.0 \mathrm{ml}), \mathrm{HCl}$ aq. $(2.0 \mathrm{ml}, 2.0 \mathrm{M}, 4.0 \mathrm{mmol})$, room temperature, 24 hours. ${ }^{c} \mathrm{CH}_{2} \mathrm{Cl}_{2}(2.0 \mathrm{ml}), \mathrm{Et}_{3} \mathrm{~N}(223 \mu \mathrm{l}, 1.6 \mathrm{mmol}, 4.0$ equiv.), benzoyl chloride (84.3 mg, $0.6 \mathrm{mmol}, 1.5$ equiv.). ${ }^{d 1} \mathrm{H}$ NMR yield of the coupling product (hydroamination step) in the crude reaction mixture using 1,3,5-trimethoxybenzene as internal standard. ${ }^{e}$ ee of $\mathbf{1 a}$ was determined by chiral HPLC. ${ }^{f}$ Yield is that of the isolated product of 1a. ${ }^{g}$ Acetonitrile was used as solvent.

test the feasibility of its asymmetric variant. The $(S)$-Segphos ligand (L2) only led to $10 \%$ of the desired product. The $(R, R)$ DIOP (L3) gave $76 \%$ of the isolated amide product 1a, while only moderate ee was obtained. Further screening led to the discovery of Josiphos (L4), which afforded 1a with $72 \%$ yield and $92 \%$ ee. $^{13}$

With the optimized conditions in hand, we then investigated the feasibility of various allene substrates (Scheme 3, 1a-i). Interestingly, in basically all cases perfect regioselectivities and excellent enantioselectivities were observed. Allenes containing alkyl substituents as well as ether, thio ether, phthalimide and sulfone functional groups were well tolerated.

Direct synthesis of branched allylic amides using simple amides and allenes was difficult. However, a one-pot synthesis of branched allylic amides or carbamate can be achieved easily upon acylation or sulfonylation of the crude allylic amine with the corresponding acyl/sulfonyl chlorides or anhydride, respectively (Scheme 3, 2a-d).

Hydroamination with bioactive moieties containing substrates using the scope conditions resulted in the desired branched allylic amines with high yields and excellent enantioselectivities (Scheme 3, 3a-c).

To test the practicality of this method for primary amine synthesis, chiral allylic amine $\mathrm{HCl}$ salt 4 was synthesized under scope conditions in a 1.1 gram scale with $86 \%$ yield and $95 \%$ ee. The released ammonia carrier (benzophenone) can be recycled after hydrolysis with 96\% yield (Scheme 4).

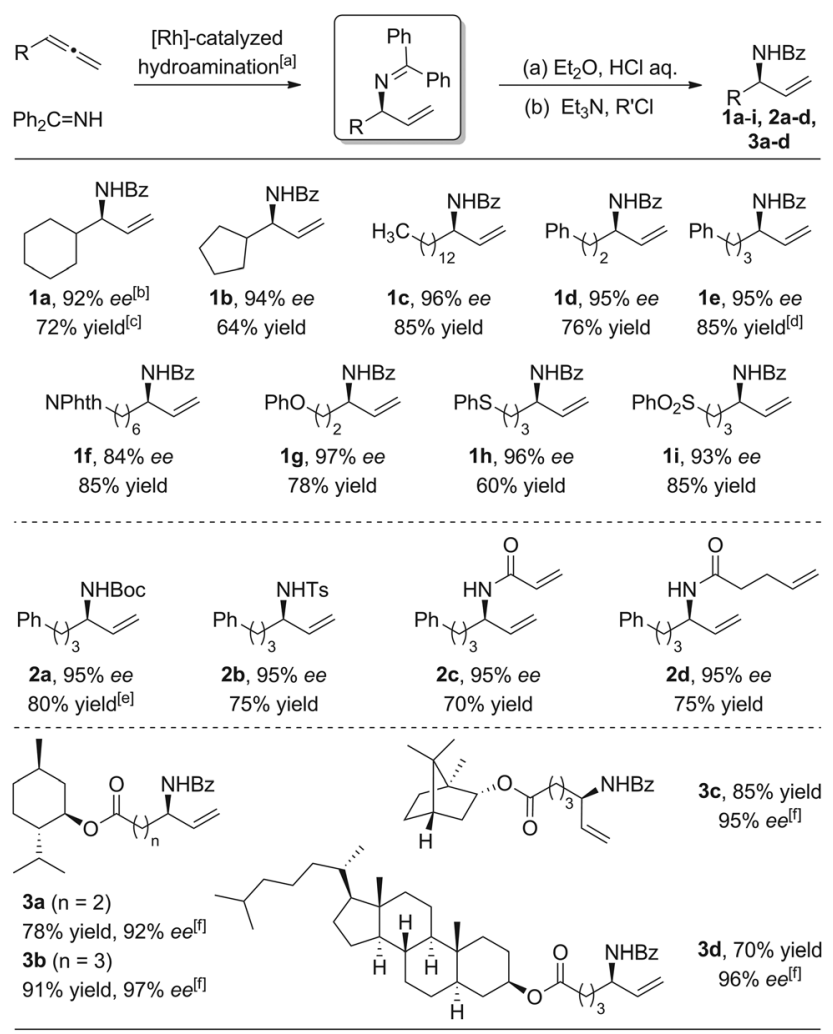

Scheme 3 Scope of allenes and one-pot synthesis of allylic amides. [a] Benzophenone imine (1.0 equiv., $0.4 \mathrm{mmol}$ ), allene (1.5 equiv.), $\left[\left\{\mathrm{Rh}(\mathrm{COD}) \mathrm{Cl}_{2}\right](2.0 \mathrm{~mol} \%), \mathrm{L} 4(4.0 \mathrm{~mol} \%), \mathrm{PPTS}(20 \mathrm{~mol} \%), \mathrm{DCE}(1.0\right.$ $\mathrm{ml})$. [b] Determined by chiral HPLC. [c] Yield is that of the isolated product. [d] The reaction was performed in $0.2 \mathrm{mmol}$ scale. [e] $\mathrm{Boc}_{2} \mathrm{O}$ was used in the protection step. Phth = phthaloyl; Ts $=4$-methylbenzene-1-sulfonyl. [f] Determined by chiral HPLC after transesterification with ethanol.

To exemplify the utility of chiral allylic amines, derivatization of compound 2 a was performed (Scheme 5). Ozonolysis of 2a followed by treatment with triphenylphosphine and $\mathrm{NaBH}_{4}$ gave $\beta$-amino alcohol $\mathbf{5 a}$ and $\alpha$-amino aldehyde $\mathbf{5} \mathbf{b}$, respectively. Direct oxidation of $2 a$ could afford $\alpha$-amino acid 5c. Hydroboration of 2a using 9-borabicyclo(3.3.1)nonane (9-BBN), then oxidation with $\mathrm{H}_{2} \mathrm{O}_{2}$ led to the formation of $\gamma$-amino alcohol 5d, which could be further oxidized to the corresponding $\beta$-amino aldehyde $5 \mathbf{e}$ and $\beta$-amino acid $\mathbf{5 f}$.

Isotopic labeling experiments using deuterated benzophenone imine $\left(\mathrm{Ph}_{2} \mathrm{C}=\mathrm{ND}\right)$ and deuterated PPTS (D-PPTS) were conducted under scope conditions. ${ }^{\mathbf{1 3}}$ Deuterium incorporation was only observed at the internal position of the allylic double bond. Hence, we suggest that the mechanism follows a similar

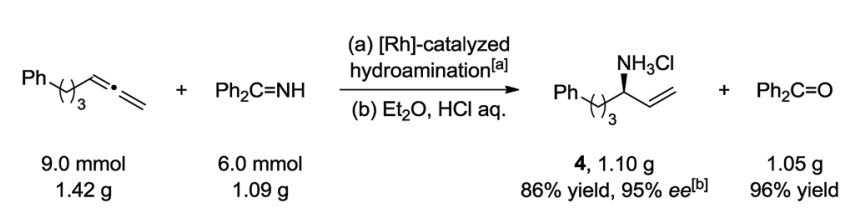

Scheme 4 Large scale synthesis of primary allylic amine. [a] Scope conditions. [b] Determined by its amide derivative 1e via chiral HPLC. 

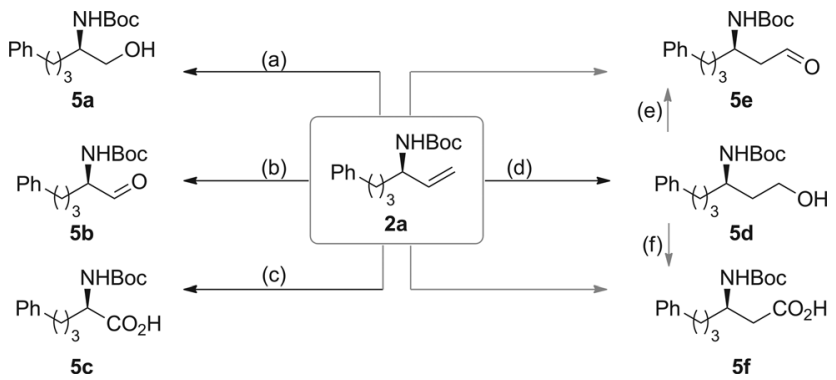

Scheme 5 Synthetic transformations of chiral allylic amines. (a) $\mathrm{O}_{3}$, $\mathrm{CH}_{2} \mathrm{Cl}_{2},-78{ }^{\circ} \mathrm{C}$; then $\mathrm{NaBH}_{4}, \mathrm{CH}_{3} \mathrm{OH}, 0{ }^{\circ} \mathrm{C}$ to r.t.; $90 \%$ yield, $95 \%$ ee (5a). (b): $\mathrm{O}_{3}, \mathrm{CH}_{2} \mathrm{Cl}_{2},-78{ }^{\circ} \mathrm{C}$; then $\mathrm{PPh}_{3},-78{ }^{\circ} \mathrm{C}$ to r.t.; $85 \%$ yield, $95 \%$ ee (5b). (c): $\mathrm{RuCl}_{3}, \mathrm{NalO}_{4}, \mathrm{MeCN} / \mathrm{CCl}_{4} / \mathrm{H}_{2} \mathrm{O}$ (1/1/1.5), r.t.; $82 \%$ yield, $95 \%$ ee (5c). (d) $9-\mathrm{BBN}, \mathrm{THF},-78{ }^{\circ} \mathrm{C}$ to r.t.; then $\mathrm{EtOH}, \mathrm{NaOH}, \mathrm{H}_{2} \mathrm{O}_{2}(30 \%)$, $-10{ }^{\circ} \mathrm{C}$ to r.t.; $95 \%$ yield, $95 \%$ ee (5d). (e): $\mathrm{C}_{5} \mathrm{H}_{5} \mathrm{NSO}_{3}, \mathrm{Et}_{3} \mathrm{~N}, \mathrm{DMSO}, 0^{\circ} \mathrm{C}$ to r.t.; $88 \%$ yield, $95 \%$ ee (5e) (f) $\mathrm{Phl}(\mathrm{OAc})_{2}$, TEMPO, $\mathrm{CH}_{3} \mathrm{CN} / \mathrm{H}_{2} \mathrm{O}(1 / 1)$, r.t.; $48 \%$ yield, $95 \%$ ee $(5 \mathrm{f})$.

pathway as for previously reported coupling reactions. ${ }^{9 e}$ Oxidative addition of the benzophenone imine $\mathrm{N}-\mathrm{H}$ bond to $\mathrm{Rh}(\mathrm{I})$ generates $\mathrm{Rh}(\mathrm{III})$ complex. Hydrometalation of the less substituted double bond could generate $\sigma$-allyl-Rh complex, which is in equilibrium with the $\pi$-allyl-Rh complex. Reductive elimination of the allyl-Rh complexes generates the branched $N$ allylic amine.

To conclude, we have developed the first highly regio- and enantioselective hydroamination of allenes using benzophenone imine as an ammonia carrier via a rhodium/Josiphos catalyst system. The reaction gave valuable $\alpha$-chiral primary allylic amines and $\alpha$-chiral allylic amides in a practical manner. Recycle of the ammonia carrier with high yield maximized the atom-economy of this protocol. Applications of this method in target oriented synthesis and using more challenging terminal alkyne as the coupling partner for the enantioselective synthesis of branched allylic amines are currently under way in our laboratories and will be reported in due course.

\section{Acknowledgements}

This work was supported by the DFG, the International Research Training Group "Catalysts and Catalytic Reactions for Organic Synthesis" (IRTG 1038) and the Krupp Foundation. We thank Umicore, BASF and Wacker for generous gifts of chemicals.

\section{Notes and references}

1 (a) T. C. Nugent, Chiral Amine Synthesis, Wiley, 2010; (b) D. J. Drucker, Lancet, 2006, 368, 1696-1705; (c) D. J. Heal, S. C. Cheetham and S. L. Smith, Neuropharmacology, 2009, 57, 608-618; (d) V. A. Ostrovskii, R. E. Trifonov and E. A. Popova, Russ. Chem. Bull., Int. Ed., 2012, 61, 768-780; (e) L. Xu, J. Luo and Y. Lu, Chem. Commun., 2009, 18071821; $(f)$ K. Ishihara and K. Nakano, J. Am. Chem. Soc., 2005, 127, 10504-10505; (g) G. Cardillo and C. Tomasini, Chem. Soc. Rev., 1996, 25, 117-128.
2 (a) E. M. Skoda, G. C. Davis and P. Wipf, Org. Process Res. Dev., 2012, 16, 26-34; (b) B. M. Trost, T. Zhang and J. D. Sieber, Chem. Sci., 2010, 1, 427-440; (c) B. M. Trost and Z. Shi, J. Am. Chem. Soc., 1996, 118, 3037-3038; (d) B. M. Trost and G. Dong, J. Am. Chem. Soc., 2006, 128, 6054-6055.

3 Selected reviews on transition-metal-catalyzed allylic substitution: (a) B. M. Trost, Chem. Rev., 1996, 96, 395-422; (b) M. Johannsen and K. A. Jørgensen, Chem. Rev., 1998, 98, 1689-1708; (c) B. M. Trost and M. L. Crawley, Chem. Rev., 2003, 103, 2921-2943; (d) Z. Lu and S. Ma, Angew. Chem., Int. Ed., 2008, 47, 258-297.

4 (a) L. E. Overman, J. Am. Chem. Soc., 1976, 98, 2901-2910; (b) J. M. Bauer and R. Peters, Catal. Sci. Technol., 2015, 5, 23402346; (c) D. F. Fischer, A. Barakat, Z.-Q. Xin, M. E. Weiss and R. Peters, Chem.-Eur. J., 2009, 15, 8722-8741; (d) D. F. Fischer, Z.-Q. Xin and R. Peters, Angew. Chem., Int. Ed., 2007, 46, 7704-7707.

5 Selected review on allylic $\mathrm{C}-\mathrm{H}$ amination: $\mathrm{G}$. Liu and $\mathrm{Y}$. $\mathrm{Wu}$, Top. Curr. Chem., 2010, 292, 195-209.

6 Selected example on imine vinylation which avoids stoichiometric organometallics: A. Barchuk, M. Ngai and M. J. Krische, J. Am. Chem. Soc., 2007, 129, 8432-8433.

7 Selected examples on the asymmetric synthesis of primary allylic amines using ammonia equivalents: (a) R. Weihofen, O. Tverskoy and G. Helmchen, Angew. Chem., Int. Ed., 2006, 45, 5546-5549; (b) T. Nagano and S. Kobayashi, J. Am. Chem. Soc., 2009, 131, 4200-4201; (c) P. A. Evans and E. A. Clizbe, J. Am. Chem. Soc., 2009, 131, 8722-8723; (d) M. J. Pouy, L. M. Stanley and J. F. Hartwig, J. Am. Chem. Soc., 2009, 131, 11312-11313; (e) M. Lafrance, M. Roggen and E. M. Carreira, Angew. Chem., Int. Ed., 2012, 51, 3470-3473.

8 Selected examples on the coupling of pronucleophiles with allenes: (a) R. Zimmer, C. Dinesh, E. Nandanan and F. A. Khan, Chem. Rev., 2000, 100, 3067-3125; (b) J. Johnson and R. G. Bergman, J. Am. Chem. Soc., 2001, 123, 2923-2924; (c) S. S. Kinderman, R. Gelder, J. H. Maarseveen, H. E. Schoemaker, H. Hiemstra and F. P. J. T. Rutjes, J. Am. Chem. Soc., 2004, 126, 4100-4101; (d) R. L. Lalonde, B. D. Sherry, E. J. Kang and F. D. Toste, J. Am. Chem. Soc., 2007, 129, 2452-2453; (e) I. S. Kim and M. J. Krische, Org. Lett., 2008, 10, 513-515; $(f)$ T. Kawamoto, S. Hirabayashi, X. Guo, T. Nishimura and T. Hayashi, Chem. Commun., 2009, 3528-3530; $(\mathrm{g})$ S. B. Han, I. S. Kim, H. Han and M. J. Krische, J. Am. Chem. Soc., 2009, 131, 6916-6917; (h) J. Moran, A. Preetz, R. A. Mesch and M. J. Krische, Nat. Chem., 2011, 3, 287290; (i) P. Koschker, A. Lumbroso and B. Breit, J. Am. Chem. Soc., 2011, 133, 20746-20749; (j) C. Li and B. Breit, J. Am. Chem. Soc., 2014, 136, 862-865; (k) B. M. Trost, C. Jäkel and B. Plietker, J. Am. Chem. Soc., 2003, 125, 4438-4439; (l) K. Xu, N. Thieme and B. Breit, Angew. Chem., Int. Ed., 2014, 53, 7268-7271.

9 Selected examples on the asymmetric synthesis $N$-allylic amines via intermolecular hydroamination of allenes: $(a)$ N. Nishina and Y. Yamamoto, Angew. Chem., Int. Ed., 2006, 
45, 3314-3317; (b) K. L. Butler, M. Tragni and R. A. Widenhoefer, Angew. Chem., Int. Ed., 2012, 51, 51755178; (c) Y. Fang, P. M. Tadross and E. N. Jacobsen, J. Am. Chem. Soc., 2014, 136, 17966-17968; (d) K. Xu, N. Thieme and B. Breit, Angew. Chem., Int. Ed., 2014, 53, 2162-2165; (e) C. Li, M. Kähny and B. Breit, Angew. Chem., Int. Ed., 2014, 53, 13780-13784; (f) K. Xu, T. Gilles and B. Breit, Nat. Commun., 2015, 6, 7616-7623; (g) A. M. Haydl, K. Xu and B. Breit, Angew. Chem., Int. Ed., 2015, 54, 7149-7153.

10 (a) Oxidative addition of $\mathrm{N}-\mathrm{H}$ to Rhodium: O. V. Ozerov, C. Guo, V. A. Papkov and B. M. Foxman, J. Am. Chem. Soc., 2004, 126, 4792-4793; (b) Although it is beyond the scope of this article, other catalytic systems might work for the coupling of allenes with ammonia. For example the copper catalyzed hydroaminations: M. T. Pirnot, Y. Wang and S. L. Buchwald, Angew. Chem., Int. Ed., 2016, 55, 48-57.

11 Selected example on using benzophenone imine as ammonia carrier: J. P. Wolfe, J. Åhman, J. P. Sadighi, R. A. Singer and S. L. Buchwald, Tetrahedron Lett., 1997, 38, 6367-6370.

12 G. Verardo, A. G. Giumanini, P. Strazzolini and M. Poiana, Synth. Commun., 1988, 18, 1501-1511.

$13 \mathrm{See} \mathrm{ESI} \dagger$ for details. 